\title{
Kruppel-like factor 5 (KIf5) in fetal-maternal tissue during periimplantation and effects of ovarian steroid hormone antagonist on its expression during uterine receptivity of albino mice
}

Kanmuna Ray Talukdar ${ }^{* *}$, Purbajyoti Saikia ${ }^{2}$ and Hirendra N. Sarma ${ }^{1}$

\begin{abstract}
Background: Embryo implantation is a tightly regulated sequence of events regulated by ovarian steroids, estrogen and progesterone, and their downstream targets. Ovarian steroids regulate most of the genes involved in embryo implantation and pregnancy. However, some factors are not regulated by ovarian steroids, estrogen, progesterone, or both. Kruppel-like factor 5 (Klf5) is an example of an ovarian steroid-independent factor having a role in cellular proliferation, differentiation. The detailed expression profile of KIf5 during uterine receptivity and periimplantation has not been studied till now. In the present research work, an attempt was made to investigate the expression pattern of Klf5 in mice fetal-maternal tissue during periimplantation (day 4-day 8). The expressional and functional independence of KIf5 on the ovarian steroids was studied using estrogen and progesterone antagonist. The study was carried out in female Swiss albino mice of LACA strain during the periimplantation period. KLF5 was localized in the fetal-maternal tissues using the immunofluorescence technique in paraffin-embedded tissues. Ovarian steroid antagonists were administered subcutaneously from day 1 to day 3 of gestation, and the uterus was collected on the morning of day 4 . KIf5 protein and mRNA levels were studied by western blot and quantitative real-time PCR (qPCR), respectively.
\end{abstract}

Results: KLF5 was localized in the embryo, uterine luminal epithelium, glandular epithelium, and proliferating stromal cells during periimplantation. In ovarian steroid antagonist-treated groups, KLF5 was localized in the luminal and glandular epithelium and stroma. Western blot and APCR confirmed translation and transcription of KLF5 during the experimental period. The KLF5 protein level significantly increased on day 6, day 7, and day 8 when compared with day $4(P<0.05)$. The mRNA level of Klf5 increased significantly on day 7 and day 8 when compared with day $4(P<$ 0.05). In ovarian steroid antagonist-treated groups, protein and mRNA corresponding to Klf5 were observed. From this finding, it can be assumed that KIf5 may be a steroid-independent factor expressed during uterine receptivity.

Conclusion: Spatiotemporal KLF5 expression in fetal-maternal tissue was observed during the experimental period. The results suggest that Klf5 is an ovarian steroid-independent factor that may play a pivotal role in implantation, decidualization, and embryogenesis.

\footnotetext{
*Correspondence: kanmuna@gmail.com

${ }^{1}$ Molecular Endocrinology \& Reproductive Biology Research Laboratory,

Department of Zoology, Rajiv Gandhi University, Rono Hills, Itanagar,

Arunachal Pradesh 791 112, India

Full list of author information is available at the end of the article
} 
Keywords: Klf5, Uterine receptivity, Antiestrogen, Antiprogesterone, Ovarian steroids, Stromal cells, Luminal epithelium, Glandular epithelium

\section{Background}

Embryo implantation and its subsequent growth is a fine-tuned orchestrated event regulated by ovarian steroids, estrogen and progesterone, and locally produced transcriptional factors like Kruppel-like factor 5 in fetalmaternal tissue [1]. Reciprocal interaction of embryo and uterus is a prerequisite event for successful embryo implantation [2, 3]. In mice, implantation takes place on day 4.5 of pregnancy, followed by decidual cell reaction inducing receptivity in maternal tissue. The luminal epithelial cells in contact with implanting blastocyst undergo apoptosis or entosis, permitting the motile blastocyst trophectoderm to come in contact with stromal cells inducing decidualization [4-7]. This critical interaction of fetal-maternal tissue is associated with uterine receptivity and window formation, which are the primary requirement of uterine function for successful embryo implantation and its growth $[8,9]$.

Estrogen and progesterone execute their functions through nuclear estrogen receptors $(E R \alpha \& E R \beta)$ and progesterone receptors (PRA \& PRB) [10]. ER $\alpha$ is the principal factor of estrogen action for uterine receptivity and implantation [11]. On day 1 of pregnancy, preovulatory estrogen binds to stromal ER $\alpha$ and stimulates uterine epithelial cell proliferation. On day 2 of pregnancy, epithelial proliferation continues. Progesterone from newly formed corpora lutea binds with PR, initiates uterine stromal cell proliferation, and inhibits uterine epithelial cell proliferation on day 3 of pregnancy. Ovarian estrogen secretion superimposed with high progesterone secretion from corpora lutea on day 4 of pregnancy leads to extensive stromal cell proliferation, luminal epithelial differentiation, and glandular secretion rendering the uterus receptive for implantation [12-14].

The synergistic action of two vital ovarian hormones, estrogen and progesterone, is the sine qua non for embryo implantation during this critical period. Most of the genes necessary for uterine receptivity, window formation, and implantation are induced and controlled by ovarian steroids during this critical period of fetalmaternal tissue interaction. In addition, some proteins have recently been identified whose expressions are not altered by the ovarian steroid hormones but have a pivotal role in receptivity and window formation for successful implantation [13]. Kruppel-like factor 5 (Klf5), a zinc-finger-containing transcription factor, is known to be an example of ovarian steroid-independent protein. Deletion of uterine Klf5 leads to female infertility because of retention of luminal epithelium around the implantation chamber and restricted embryonic growth [13, 15]. Klf5 is an essential factor for blastocyst development, as the Klf5 deficient mouse embryos fail to implant due to defective trophectoderm development. It is also required for the derivation of ESCs from inner cell mass (ICM) cells [16] and primitive endoderm development in the preimplantation mouse embryo [17]. In the uterus, Klf5 expression is unresponsive to changes in ovarian steroid hormone; however, a detailed in situ expression of this transcription factor in fetal-maternal tissue during early gestation is yet to be elucidated.

In this present investigation, we are going to study the expression pattern of this transcription factor in mice during periimplantation (day 4 to day 8). In situ localization will show the distribution pattern of KLF5 in fetal-maternal tissue. Estrogen and progesterone signalling is inevitable for the growth and development of the embryo and changes in maternal tissue for uterine receptivity, implantation, decidualization, and maintenance of pregnancy. In the present investigation, we administered estrogen and progesterone receptor antagonists to experimental females to study the expression pattern of Klf5 in the absence of native ovarian steroid action on the uterus.

\section{Methods}

\section{Experimental animals}

Swiss albino mice of LACA strain were purchased from the Directorate of health services, Shillong, India. The animals were acclimatized for 2 weeks before starting the experimental procedures. According to the Institutional Animal Ethical Committee of Rajiv Gandhi University, mice were maintained in the animal facility. The experimental protocols used in the present investigation were approved by the Institutional Animal Ethical Committee, Rajiv Gandhi University. Mice were housed in the animal care facility in the natural light-dark cycle and provided with food and water ad libitum.

\section{Experimental design and sample collection}

The adult female mice undergoing normal estrous cycle were selected for the present investigation by studying vaginal smear cytology. Adult cyclic virgin females (25-30-g weight, 6-8 weeks old) were kept for mating with a male of known fertility in the ratio 2:1 (2 female: 1 male). The presence of a vaginal plug or the observation of sperm in the vaginal smear on the next morning was 
considered day 0.5 of pregnancy. The implantation sites were studied using an intravenous injection of 1\% Chicago blue Dye (Sigma-Aldrich, Catalog no. C8679-25G) prepared in $0.9 \%$ saline in the tail vein 15 min prior to the collection of the uterine tissues $[18,19]$. Mice were euthanized by cervical dislocation, and uterine tissues of pregnant mice from day 5 (D5) to day 8 (D8) of gestation were collected accordingly.

An experimental design of administration of antiestrogen (AntiE2), antiprogesterone (AntiP4) and antiestrogen + antiprogesterone (AntiE2+P4) has been presented in Fig. 1. Antiestrogen, ICI 182,780 (Faslodex/Fulvestrant) (Sigma-Aldrich) prepared in sesame oil was injected subcutaneously at the dose of $100 \mu \mathrm{g} / 100 \mu \mathrm{l}$ [20]. antiprogesterone, mifepristone (RU486) (Sigma-Aldrich), was prepared in sesame oil at the dose of $200 \mu \mathrm{g} / 100 \mu \mathrm{l}$ [21]. Antiestrogen and antiprogesterone were given together at the dose of $100+200 \mu \mathrm{g} / 100 \mu \mathrm{l}$ of sesame oil. Steroid antagonists were administered subcutaneously from day 1 to day 3 of gestation at $09.00 \mathrm{~h}$, and samples were collected on day 4 morning. Mice were administered vehicle (100 $\mu \mathrm{l}$ sesame oil) from days $1-3$, and uterine samples were collected on the morning of day 4 . Forty mice were divided into eight groups (D4 control, D5, D6, D7, D8, AntiE2 treated, AntiP4 treated, and AntiE2+P4 treated), and each group contained five animals. The sample size was decided, considering similar studies from the laboratory.

\section{Histological staining of uterine section}

The uterine tissue samples collected were washed in PBS and fixed in Bouin's fluid for a period of $72 \mathrm{~h}$. Fixed tissues were washed, dehydrated through graded series of alcohol and finally embedded in a paraffin block. Paraffin-embedded tissues were cut in the serial section of 5 - $\mu \mathrm{m}$ thickness and mounted on poly-L-lysine (SigmaAldrich, Catalog no. P 4707) coated glass slide. Hematoxylin and Eosin (H\&E) staining was performed following a standard protocol to study the detailed structure of uterine tissue sections.

\section{Immunofluorescent localization of KLF5}

Immunofluorescent localization of KLF5 was performed in the paraffin-embedded tissue sections [22]. Briefly, the paraffin-embedded sections were deparaffinized in xylene and rehydrated in graded series of alcohol (from $100 \%$ to $30 \%$ ) and finally in distilled water. Briefly, Heat Induced Epitope Retrieval (HIER) was performed using citrate buffer ( $\mathrm{pH}$ 6.0) for $1 \mathrm{~h}$. Sections were washed in PBS, 3 times for $5 \mathrm{~min}$ each. The sections were permeabilized in $0.1 \%$ PBS-T for 10 min. 5\% Normal Goat Serum (NGS) was used to block nonspecific binding sites of the tissues for $1 \mathrm{~h}$ in a humidified chamber. Sections were treated with rabbit polyclonal primary antibody (Santacruz Biotech, KLF5, sc-22797) diluted in PBS-BSA at $2.5 \mu \mathrm{g} / \mathrm{ml}$ concentration at $4{ }^{\circ} \mathrm{C}$ overnight. To remove the unbound primary antibody, washing of the sections was done in PBS, 3 times for 5 min each. Sections were incubated with Goat anti-rabbit secondary antibody (Santacruz Biotech, FITC tagged, sc-2012) for $2 \mathrm{~h}$ in a dark, humidified chamber. Sections were thoroughly washed in PBS (3 times for 5 min each) to remove any unbound secondary antibody. Sections were mounted with mounting media (90\% Glycerol in PBS). Negative control was performed by using normal Rabbit IgG instead of KLF5 primary antibody. Immunofluorescent signal imaging was

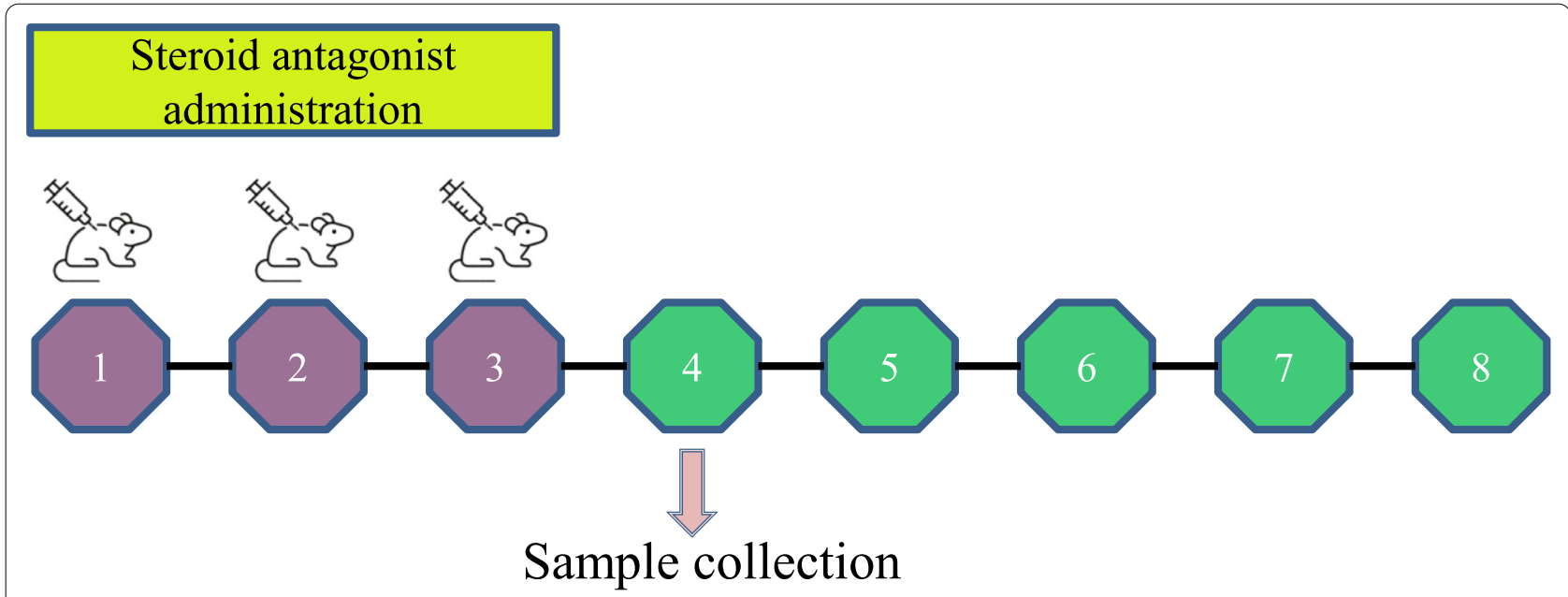

Fig. 1 Schematic representation of ovarian steroid antagonist administration regimen. Antiestrogen $(100 \mu \mathrm{g} / 100 \mu \mathrm{l})$, antiprogesterone (200 $\mu \mathrm{g} / 100 \mu \mathrm{l})$, and antiestrogen + antiprogesterone $(100+200 \mu \mathrm{g} / 100 \mu \mathrm{l})$ injected subcutaneously from D1 to D3 in 3 different groups. Uterine tissue samples were collected on D4 at $0900 \mathrm{~h}$ 
done in Leica DM 5000B microscope (Leica Microsystems, Germany). Quantification of KLF5 immunofluorescent signal intensity was performed by ImageJ software (NIH, USA).

\section{Western blot of KLF5}

The uterine tissue samples collected were homogenized in RIPA extraction buffer on ice using a homogenizer. Homogenate was kept on ice for $30 \mathrm{~min}$ and centrifuged at $11,700 \mathrm{~g}$ for $25 \mathrm{~min}$. The supernatant was collected in a fresh centrifuge tube and was kept at $-20{ }^{\circ} \mathrm{C}$ until further processing. Quantitative estimation of protein was performed by Lowry assay [23], keeping BSA as a standard using Multiskan GO (Thermo Scientific). Proteins were separated in 12\% SDS-PAGE [24] using Mini-PROTEAN Tetra Cell Electrophoretic Apparatus (Bio-Rad). Briefly, the separated proteins were transferred to nitrocellulose membrane using Mini Trans-Blot Electrophoretic Transfer Cell (Bio-Rad) for $1 \mathrm{~h}$ at $100 \mathrm{~V}$. Nonspecific binding was blocked by $5 \%$ non-fat dry milk for $2 \mathrm{~h}$ and briefly washed in TBS-T. The nitrocellulose membrane was incubated with rabbit polyclonal KLF5 antibody (Santacruz Biotech, sc-22797) prepared in TBS at $4{ }^{\circ} \mathrm{C}$ overnight and washed in TBS for 5 min followed by washing in TBS: TBS-T (1:1) for $5 \mathrm{~min}$. The membrane was incubated with mouse anti-rabbit secondary antibody (Santacruz Biotech, sc-2357) diluted in TBS: TBS-T for $2 \mathrm{~h}$ at room temperature. Excess secondary antibody was removed by washing with TBS. Finally, the membrane was developed with TMB $\left(3,3^{\prime}, 5,5^{\prime}\right.$-tetramethylbenzidine). $\beta$-actin was used as an internal control. Densitometric analysis of Western blot bands was performed by ImageJ software (NIH, USA).

\section{Real-time PCR}

Total RNA of uterine samples was extracted for quantification of mRNA transcript by real-time PCR [25]. TRIzol reagent (Invitrogen, Catalog no. 15596026) was used for the extraction of RNA following the manufacturer's protocol. Briefly, concentration and quality assessment of RNA was performed by Nanodrop 2000c (Thermo Scientific, USA). $5 \mu \mathrm{g}$ RNA was used for reverse transcription of RNA to cDNA using iScript ${ }^{\mathrm{TM}}$ cDNA synthesis kit (Bio-Rad, Catalog no. 170-8891) following manufacturer's protocol. The primers used for mouse Klf5 and housekeeping gene GAPDH have been added in Table 1.

Reverse transcriptase quantitative polymerase chain reaction (RT-qPCR) was performed using $\mathrm{iTaq}^{\mathrm{TM}}$ Universal SYBR Green Supermix (Bio-Rad, Catalog no. 1725121). Briefly, the RNA template, primer and reaction buffer were thawed at room temperature and placed in ice for the preparation of the reaction mix. $20 \mu \mathrm{l}$ reaction mix was prepared according to the instruction
Table 1 Primers for Klf5 and GAPDHtable

\begin{tabular}{|c|c|c|c|}
\hline Gene symbol & Accession no. & Primer sequence $\left(5^{\prime}-3^{\prime}\right)$ & $\begin{array}{l}\text { Amplicon } \\
\text { size (bp) }\end{array}$ \\
\hline Klf5 & NM_009769.4 & $\begin{array}{l}\text { CTACTTTCCCCCGTCACCAC } \\
\text { TAAAGGATGGCAGAGCGG } \\
\text { AC }\end{array}$ & 539 \\
\hline GAPDH & NM_008084 & $\begin{array}{l}\text { TCACTGCCACCCAGAAGA } \\
\text { GACGGACACATTGGGGGT } \\
\text { AG }\end{array}$ & 186 \\
\hline
\end{tabular}

manual provided. Reaction mix without template RNA was pipetted out in the 96 well PCR plate. RNA template was added to each well accordingly and mixed. A No Template Control (NTC) was incorporated in the experiment to check the specificity of primer. The cycling condition of the Bio-Rad real-time system was set as follows: Polymerase activation and DNA denaturation at $95^{\circ} \mathrm{C}$ for $3 \mathrm{~min}$, followed by 40 cycles of denaturation at $95^{\circ} \mathrm{C}$ for $5 \mathrm{~s}$ and annealing at $60^{\circ} \mathrm{C}$ for $30 \mathrm{~s}$. At the end of the run, data were analyzed by Bio-Rad CFX manager software, version 3.1. All the reactions were run in triplicate. Data were normalized to GAPDH expression using the $2^{-\Delta \Delta \mathrm{Ct}}$ method [26].

\section{Statistical analysis}

The data of immune-signal intensity (Immunofluorescence), western blotting and Real-time PCR of Klf5 were statistically analyzed using the Statistical Package for Social Sciences (SPSS, version 16.0). The data of immunofluorescence, western blot and Real-time PCR on D4 of gestation were compared with other data. All the data have been presented as Mean value \pm Standard Error (SE). One way ANOVA (Analysis of variance) with LSD Post Hoc test was performed to know the statistical difference. $P<0.05$ was considered statistically significant for all tests.

\section{Results}

\section{Immunofluorescent localization of KLF5} Day 4 (D4)

The histological structure of mouse uterus on D4 of gestation has been presented in Fig. 2a. The expression pattern of KLF5 in the uterus on D4 of mice pregnancy has been presented in Fig. $2 b-d$. The uterine lumen in the apposition stage was observed in the uterine section. Several uterine glands of circular and elongated shape embedded in the stromal cell layer were observed in the uterine section on D4 of pregnancy. In the D4 mouse uterine section, KLF5 was localized in the luminal epithelium (LE), the glandular epithelium (GE) and the proliferating stromal cells (PSC), as shown in Fig. 2b-d. Moderate intensity of Immunostaining signal was reported in the luminal epithelium (LE) on D4 of 

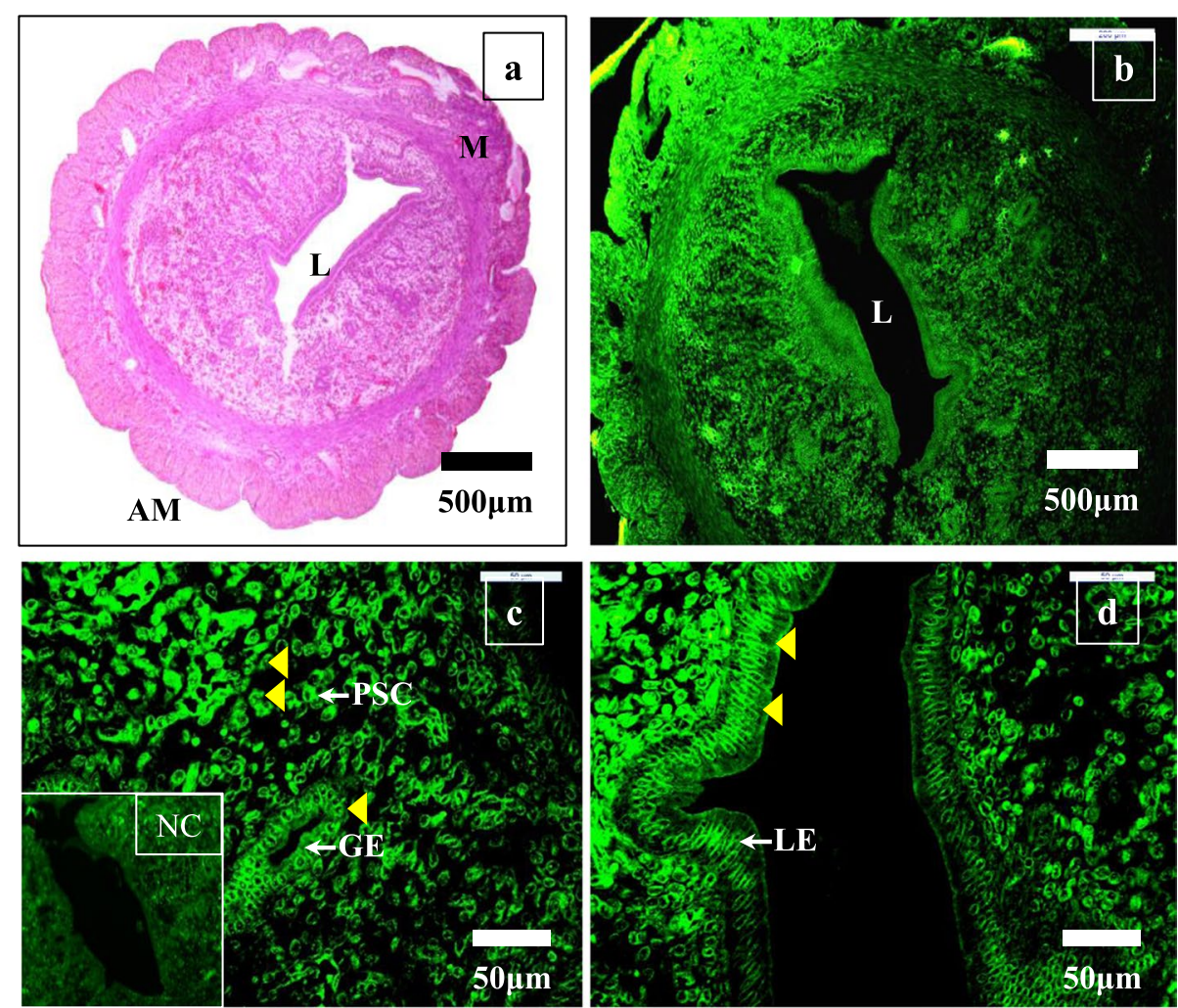

Fig. 2 Immunofluorescent localization of KLF5 on D4 mice uterus using FITC-conjugated antibody. The protein was localized in the luminal epithelium (LE) and glandular epithelium (GE) of uterine glands and the proliferating stromal cell (PSC). The arrowhead indicates the expression. Original magnification: a 5x, b 5x, c 40x, d 40x. L, lumen; M, mesometrial pole; AM, antimesometrial pole; NC, negative control

pregnancy. In the glandular epithelium (GE) and stromal layer, strong intensity of immunosignal was observed. The quantitative analysis of the immunofluorescent signal in different cell types of embryonic and uterine tissue has been listed in Table 2 .

\section{Day 5 (D5)}

The structural organization of fetal-maternal tissue on day 5 of gestation in mice stained with Hematoxylin and eosin (HE) has been presented in Fig. 3a. The expression pattern of KLF5 in the uterus on D5 of mice

Table 2 Compartment specific expression profile of KLF5 during D4-D8 of gestation and in AntiE2-, AntiP4-, and AntiE2+P4-treated females. Samples of ovarian steroid antagonist-treated group were collected on the morning of D4. Immunofluorescence signal was quantified in various embryonic and uterine cell types by ImageJ software. Intensity values are expressed as means of observations ( $n$ $=5$, mean value \pm standard error, $P<0.05)$. E, embryo, $E P C$, ectoplacental cone; $L E$, luminal epithelium, GE, glandular epithelium; $P D Z$, primary decidual zone; $S D Z$, secondary decidual zone

\begin{tabular}{|c|c|c|c|c|c|c|c|}
\hline Sample & $E$ & EPC & LE & GE & Stroma & PDZ & SDZ \\
\hline D4 & --- & --- & ++ & +++ & +++ & --- & --- \\
\hline D5 & ++ & --- & ++ & +++ & +++ & +++ & --- \\
\hline D6 & +++ & ++ & ++ & ++ & ++ & ++ & +++ \\
\hline D7 & +++ & +++ & + & --- & ++ & ++ & ++++ \\
\hline D8 & ++++ & ++++ & --- & --- & ++ & + & ++++ \\
\hline AntiE2 & --- & --- & ++++ & +++ & +++ & --- & --- \\
\hline AntiP4 & --- & --- & ++++ & ++ & +++ & --- & --- \\
\hline AntiE2+P4 & --- & --- & ++ & ++ & +++ & --- & --- \\
\hline
\end{tabular}

$+<20 \%$ (low) $++20-40 \%$ (moderate) $+++40-80 \%$ (strong) $++++>80 \%$ (intense),--- (signal absent) 

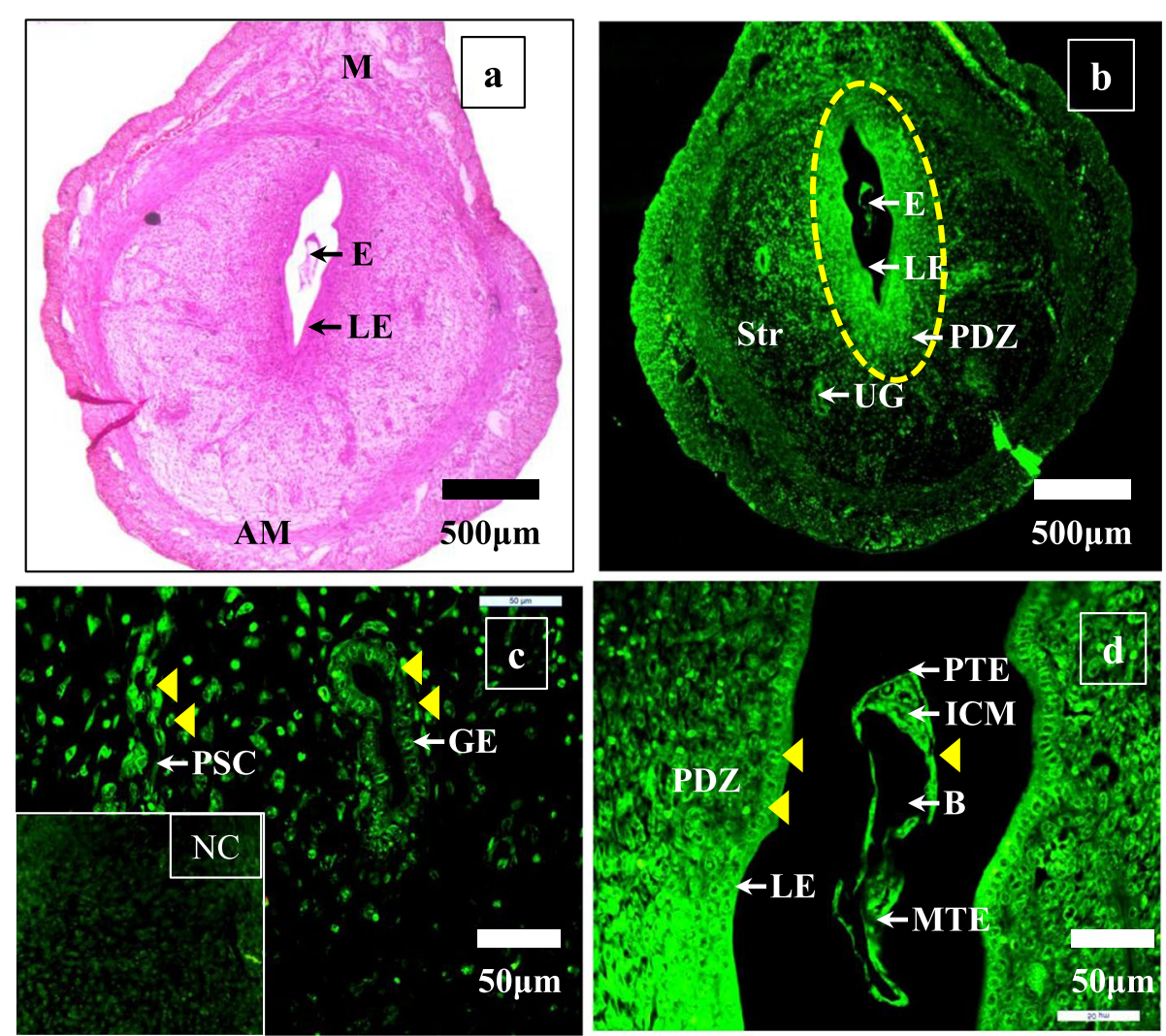

Fig. 3 Immunofluorescence of KLF5 on D5 mice uterus using FITC-conjugated antibody. The KLF5 protein was localized in the luminal epithelium (LE), glandular epithelium (GE) of uterine glands, embryo (E), and proliferating stromal cell (PSC) of the primary decidual zone (PDZ). The arrowhead indicates the expression. Original magnification: a 5x, b 5x, c 40x, d 40x. Str, stroma; ICM, inner cell mass; B, blastocoel; PTE, polar trophectoderm; MTE, mural trophectoderm, $M$, mesometrial pole; AM, antimesometrial pole, NC, negative control

pregnancy has been presented in Fig. 3b-d. The luminal epithelium in apposition stage and embryo in blastocyst stage with Inner cell mass (ICM), blastocoel (B) and trophectoderm (TE) was observed in the D5 uterine section. In mice, ICM is facing towards the mesometrial pole. The polar trophectoderm covers the embryo on the ICM side, whereas the mural trophoblast covers the blastocoel. Stromal cells adjacent to implanting blastocyst undergo decidual cell reaction and become multinucleated decidual cells forming avascular primary decidual zone (PDZ). On D5 of mouse pregnancy, the KLF5 protein was localized in embryonic cells, luminal epithelium (LE), glandular epithelium (GE), and proliferating stromal cells (PSC) of the primary decidual zone (PDZ). KLF5 was localized in the inner cell mass (ICM) and trophectoderm layer (TE) of the embryo. Moderate intensity of immunostaining signal was detected in the embryo and luminal epithelium. In the glandular epithelium and stroma, a strong immunosignal intensity was reported (Table 2).

\section{Day 6 (D6)}

Figure 4 a represents the HE stained histological structural organization of fetal-maternal tissue in mice uterus on day 6 of gestation. Figure $4 \mathrm{~b}-\mathrm{d}$ shows the expression pattern of KLF5 in the uterus of D6 pregnant mice. The rapid growth of the embryo commences with the beginning of implantation. Blastocoel enlarges and forms the yolk cavity, and the embryoblast (ICM) grow in the cavity and become cylindrical in shape termed as egg cylinder. The polar trophectoderm forms extra-embryonic ectoderm and ectoplacental cone (EPC), whereas, mural trophectoderm gives rise to trophoblast giant cells (TGC). The trophoblasts invade the luminal epithelium towards the antimesometrial pole to come in contact with stromal cells. The stromal cells which come in direct contact with the embryo undergo endoreduplication to form the primary decidual zone (PDZ). The stromal cells close to PDZ differentiate into polyploid decidual cells forming the secondary decidual zone (SDZ). Uterine lumen and vascular sinusoidal fold (VSF) were observed in the mesometrial pole. Few uterine glands were also observed 

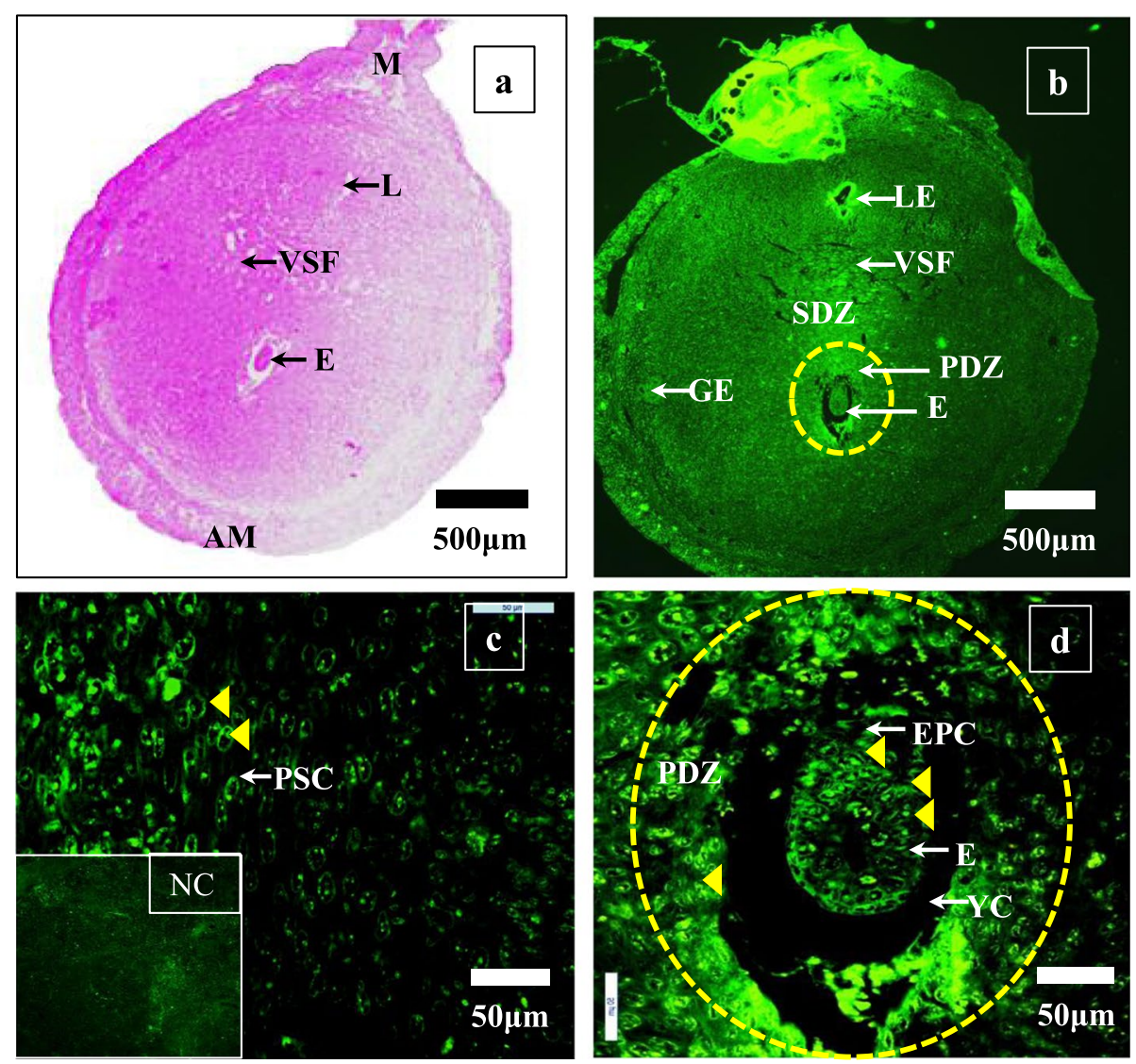

Fig. 4 Immunofluorescence of KLF5 on D6 mice uterus using FITC-conjugated antibody. The protein was localized in the luminal epithelium (LE), embryo (E), and proliferating stromal cell (PSC) of PDZ and secondary decidual zone (SDZ). The arrowhead indicates the expression. Original magnification: a 5x, b 5x, c 40x, d 40x. YC, yolk cavity; EPC, ectoplacental cone; VSF, vascular sinusoidal fold; M, mesometrial pole; AM, antimesometrial pole; NC, Negative control

in D6 mouse uterine section. As shown in Fig. 4b-d, KLF5 was localized in the luminal epithelium (LE), glandular epithelium (GE), primary decidual zone (PDZ), and secondary decidual zone (SDZ) as well as in embryonic cells. During D6 of gestation, strong intensity of immunosignal was observed in the embryo and SDZ. Moderate immunosignal intensity was observed in the LE, GE, ectoplacental cone (EPC) and PDZ (Table 2).

\section{Day 7 (D7)}

HE stained section of mice uterus on D7 of gestation has been presented in Fig. 5a. The expression pattern of KLF5 in the uterus on D7 of mice pregnancy has been presented in Fig. 5b-d. As the pregnancy progress, the size of the egg cylinder increase. To accommodate the growing embryo, the decidual cells of PDZ undergo apoptosis. Well-developed secondary decidual zone (SDZ) with polyploid decidual cell and vascular sinusoidal fold (VSF) was observed at this stage. The Ectoplacental cone, which arises from the active growth of the extra-embryonic ectoderm, joins the egg cylinder ventrally and extends towards the uterine lumen dorsally. Maternal blood infiltrates the ectoplacental cone, which develops into the placenta later. On D7 of mice pregnancy, KLF5 transcription factor was localized in the embryo, luminal epithelium and the proliferating stromal cells (PSC). Strong intensity of immunosignal was detected in the embryo. Whereas in the luminal epithelium, immunosignal intensity observed was low. Moderate immunosignal intensity was observed in the stroma and strong intensity in EPC (Table 2). The detailed structure of the D7 mice embryo has been shown in Fig. 6. Amniotic cavity, embryonic ectoderm, extra-embryonic mesoderm, and distal endoderm layers can be observed in the D7 mouse embryo.

\section{Day 8 (D8)}

A cross-sectional structure of developing embryo on D8 of gestation within the mice uterus stained with routine HE staining method has been presented in Fig. 7a. The expression pattern of KLF5 in the uterus on D8 of 

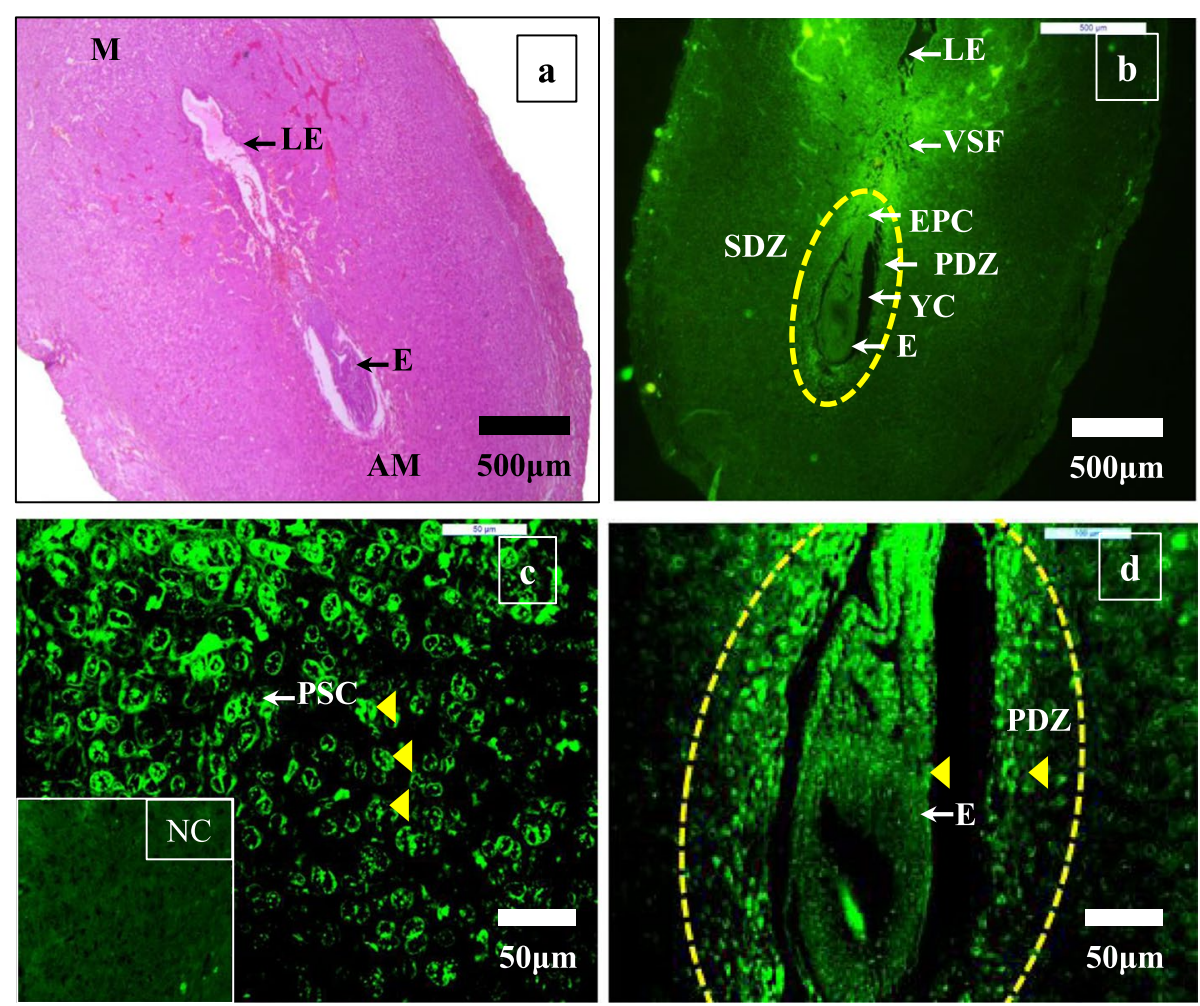

Fig. 5 Immunofluorescence of KLF5 on D7 mice uterus using FITC-conjugated antibody. The protein was localized in the luminal epithelium (LE), proliferating stromal cell (PSC), and embryo (E). The arrowhead indicates the expression. Original magnification: a $5 \times, \mathbf{b} 5 \times, \mathbf{c} 40 \times, \mathbf{d} 40 \times$. PDZ, primary decidual zone; SDZ, secondary decidual zone; YC, yolk cavity; EPC, ectoplacental cone; VSF, vascular sinusoidal fold; M, mesometrial pole; AM, antimesometrial pole; NC, negative control

mice pregnancy has been presented in Fig. $7 \mathrm{~b}-\mathrm{d}$. With the advancement of pregnancy, there are morphological changes in the embryo and the uterus. On D8 of mouse pregnancy, Trophoblast giant cells (TGC), which arise from the mural trophectoderm, can be observed surrounding the embryo. TGC are multinucleated cells as they are formed by the process of endoreduplication. The size of PDZ was smaller, as the decidual cells of this zone undergo apoptosis. Well-developed secondary decidual zone (SDZ) was observed in the uterine section on D8 of mouse pregnancy. Intense intensity of immunosignal was observed in the embryo and ectoplacental cone (EPC). In the stroma, moderate immunosignal intensity was reported (Table 2).

\section{Anti-E2 treated day 4 (AntiE2)}

HE stained uterine section of anti-E2 treated D4 mice uterus has been presented in Fig. 8a. The expression pattern of KLF5 in the uterus of anti-E2 treated D4 (AntiE2) pregnant mice has been presented in Fig. $8 \mathrm{~b}-\mathrm{d}$. The uterine lumen observed was not at the receptive stage for embryo implantation. KLF5 transcription factor was localized in the uterine luminal epithelium (LE), glandular epithelium (GE), and stroma (Str). The uterine luminal epithelial cells exhibited the KLF5 expression with intense intensity. Strong intensity of Immunostaining signal was noted in glandular epithelium and stroma (Table 2).

\section{Anti-P4 treated day 4 (AntiP4)}

The histological structure of mice uterus (HE stained) following administration of progesterone receptor antagonist on day 4 of gestation has been presented in Fig. 9a. The expression pattern of KLF5 in the uterus of anti-P4 treated D4 (AntiP4) pregnant mice has been presented in Fig. 9b-d. Non-receptive uterine lumen was observed. The KLF5 protein was localized in the uterine luminal epithelial cells (LE), glandular epithelium (GE), and stroma (Str). The intensity of immunosignal in the luminal epithelium was intense. Moderate immunosignal intensity was noted in glandular epithelial cells. In the uterine stroma, strong intensity of immunostaining signal was observed (Table 2). 


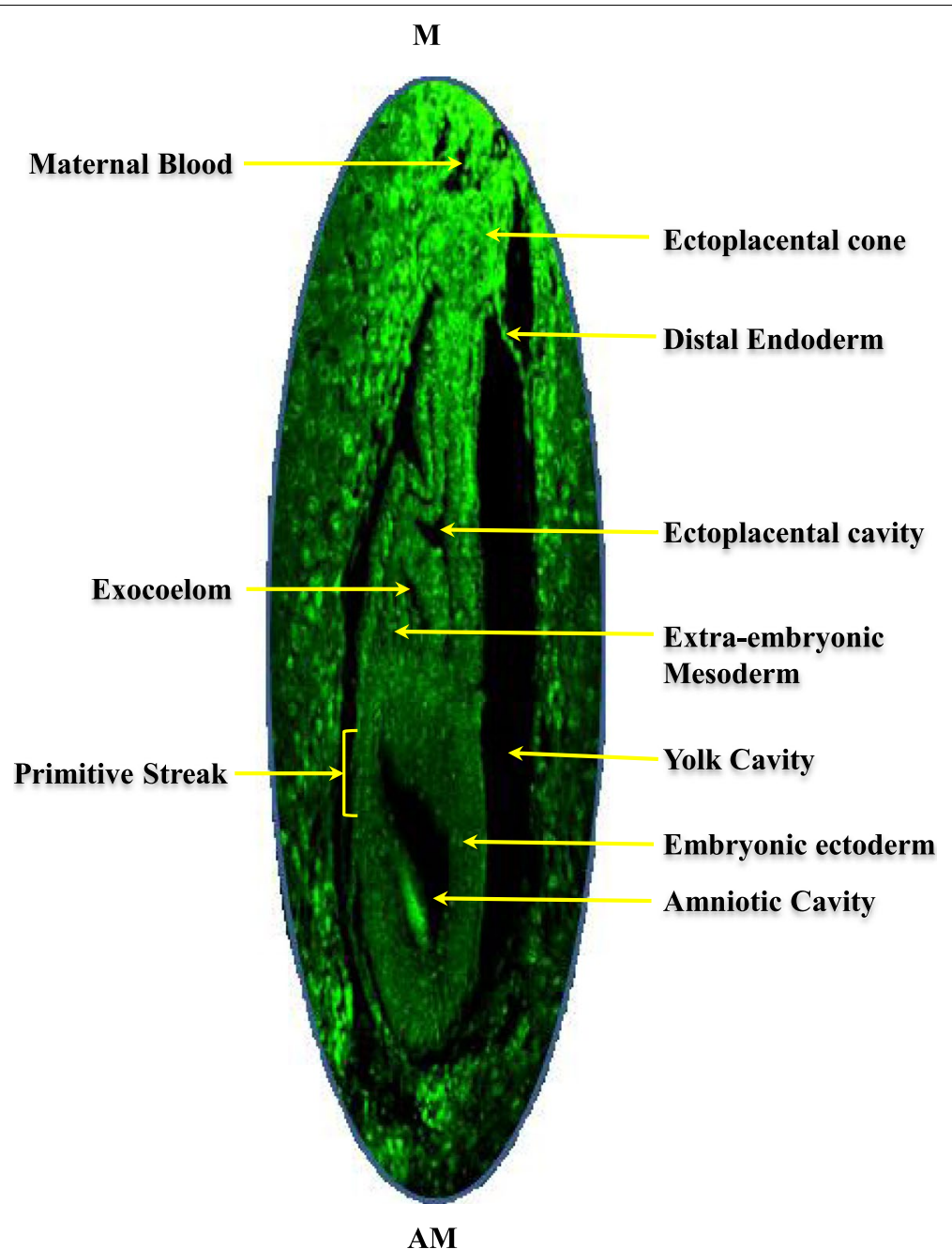

Fig. 6 Structure of D7 mice embryo and expression of KLF5 in different cell types. The transcription factor was localized in various embryonic and extra-embryonic cells. M, mesometrial pole; AM, antimesometrial pole

\section{Anti-E2+P4 treated Day 4 (AntiE2+P4)}

The histological structure of HE stained uterine section following co-treatment of estrogen and progesterone receptor antagonist (antiE2 + antiP4) on day 4 of gestation has been presented in Fig. 10a. The expression pattern of KLF5 in the uterus of anti-E2+P4 treated D4 (AntiE2+P4) pregnant mice has been presented in Fig. 10b-d. Uterine lumen did not transform into a slitlike structure which is characteristic of the receptive uterus. The KLF5 protein was immunolocalized in the luminal epithelium (LE), glandular epithelium (GE) and stromal (Str) compartments. The intensity of immunosignal in the luminal epithelium and glandular epithelium was moderate. In the stroma, strong intensity of immunosignal was noted (Table 2).

\section{Western blot analysis of KLF5 in mice uteri during periimplantation period}

Following the immunofluorescent localization of KLF5 in fetal-maternal tissue, the protein level of KLF5 during the periimplantation period (D4-D8) and in antagonist treated groups was studied by Western blot. The presence of KLF5 protein in western blot during the experimental period was observed, as shown in Fig. 11a-e. The intensity of KLF5 protein bands showed a gradual increase from D4 to D8 of pregnancy. The results showed that KLF5 reaches its maximum level on D8 of gestation. The KLF5 protein level on D5 was comparable to D4. On D6, the protein level increased as compared to D4 due to the increase in stromal cell proliferation. The KLF5 protein level increased abruptly on D7 and D8 as uterine stromal 

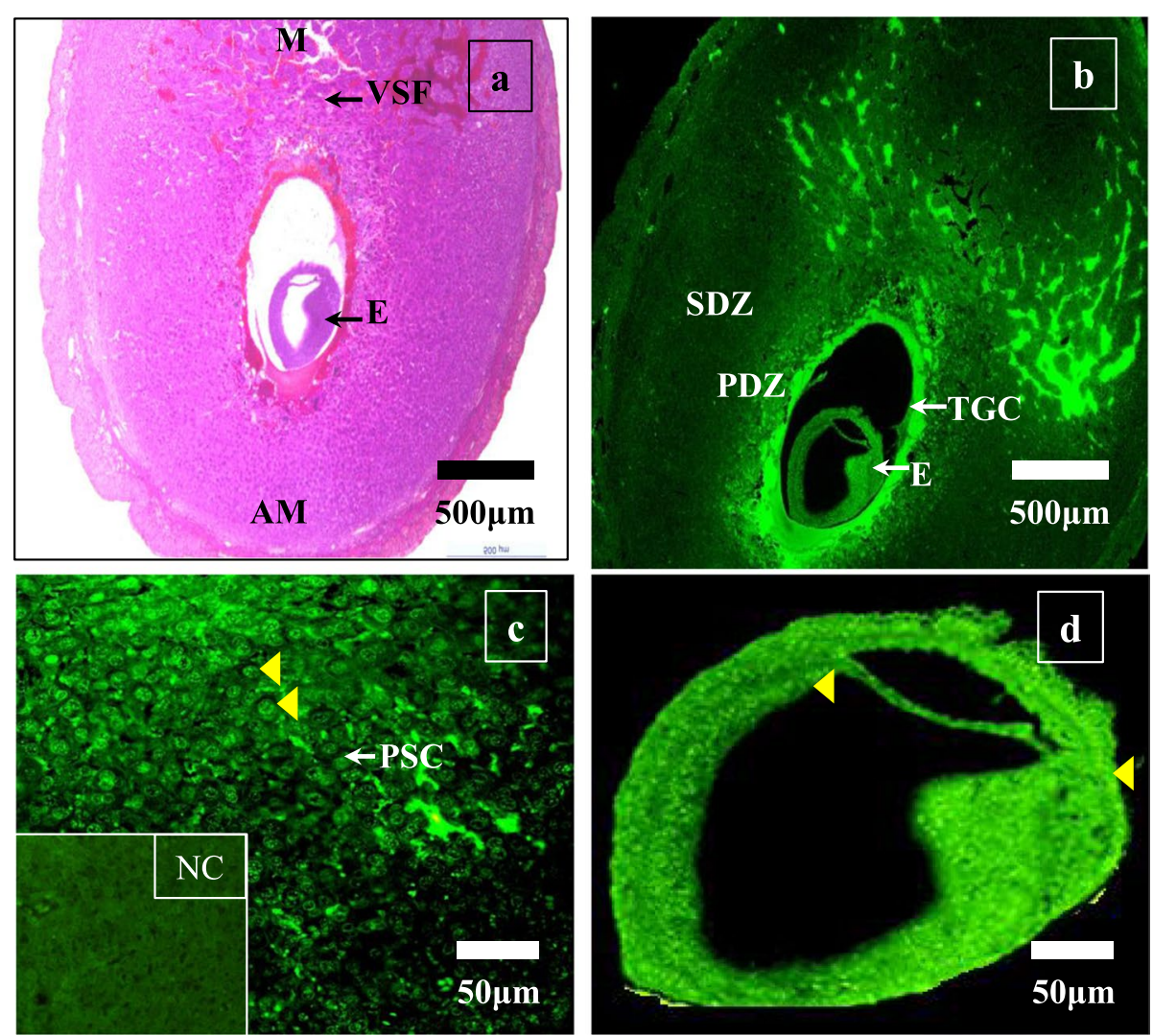

Fig. 7 Immunofluorescence of KLF5 on D8 mice uterus using FITC-conjugated antibody. The protein was localized in the proliferating stromal cell (PSC) and embryo (E). The arrowhead indicates the expression. Original magnification: a 5x, b 5x, c 40x, d 40x. M, mesometrial pole; AM, antimesometrial pole; PDZ, primary decidual zone; SDZ, secondary decidual zone; TGC, trophoblast giant cell; YC, yolk cavity; NC, negative control

cells are undergoing extensive proliferation at this period. AntiE2-treated D4 mice uterus has slightly higher protein level as compared to D4. AntiP4 and AntiE2+P4 treated D4 mouse uterus showed slightly lower protein levels when compared with D4.

Densitometric analysis showed a significant difference in the transcription factor's expression on D6, D7, D8, AntiE2, and AntiP4 treated when compared with D4 ( $P$ $<0.05)$.

\section{Real-time PCR analysis of KIf5 during periimplantation period}

The pattern of Klf5 mRNA transcript in the mice uteri during the experimental period from D4 to D8 has been presented in Fig. 12a-d. The real-time quantitative data showed a gradual increase of Klf5 mRNA transcript with the progression of gestation days. The Klf5 mRNA transcript level increased from D4 to D7. However, on D8, an abrupt increase in Klf5 mRNA transcript was observed when compared with D4. AntiE2-treated D4 mouse uterus showed a lower level of Klf5 transcript when compared with D4. The Klf5 mRNA level was higher than that of D4 in AntiP4, and AntiE2+P4 treated D4 mouse uterus. The D4 Klf5 mRNA varies significantly with D7, D8 and AntiP4 treated D4 samples $(P<0.05)$.

\section{Discussion}

Coordination of both embryo and uterus is required at the 'window of implantation (WOI)' or 'window of receptivity (WOR)' for successful embryo implantation [27]. At this particular time, the blastocyst can survive and implant in the uterine milieu, which is otherwise hostile. The collective action of two key ovarian hormones, estrogen and progesterone, is a prerequisite for embryo implantation. These hormones bind to their corresponding nuclear receptor and act on their downstream targets [28]. Most of the genes involved in embryo implantation are responsive to the two ovarian steroids. However, recently some genes have been reported which are not responsive to estrogen, progesterone, or both. Previous studies reported that Kruppel-like factor 5 (Klf5), a zinc-finger-containing transcription factor, is unresponsive to ovarian steroids in the uterus [15]. In the present investigation, we 

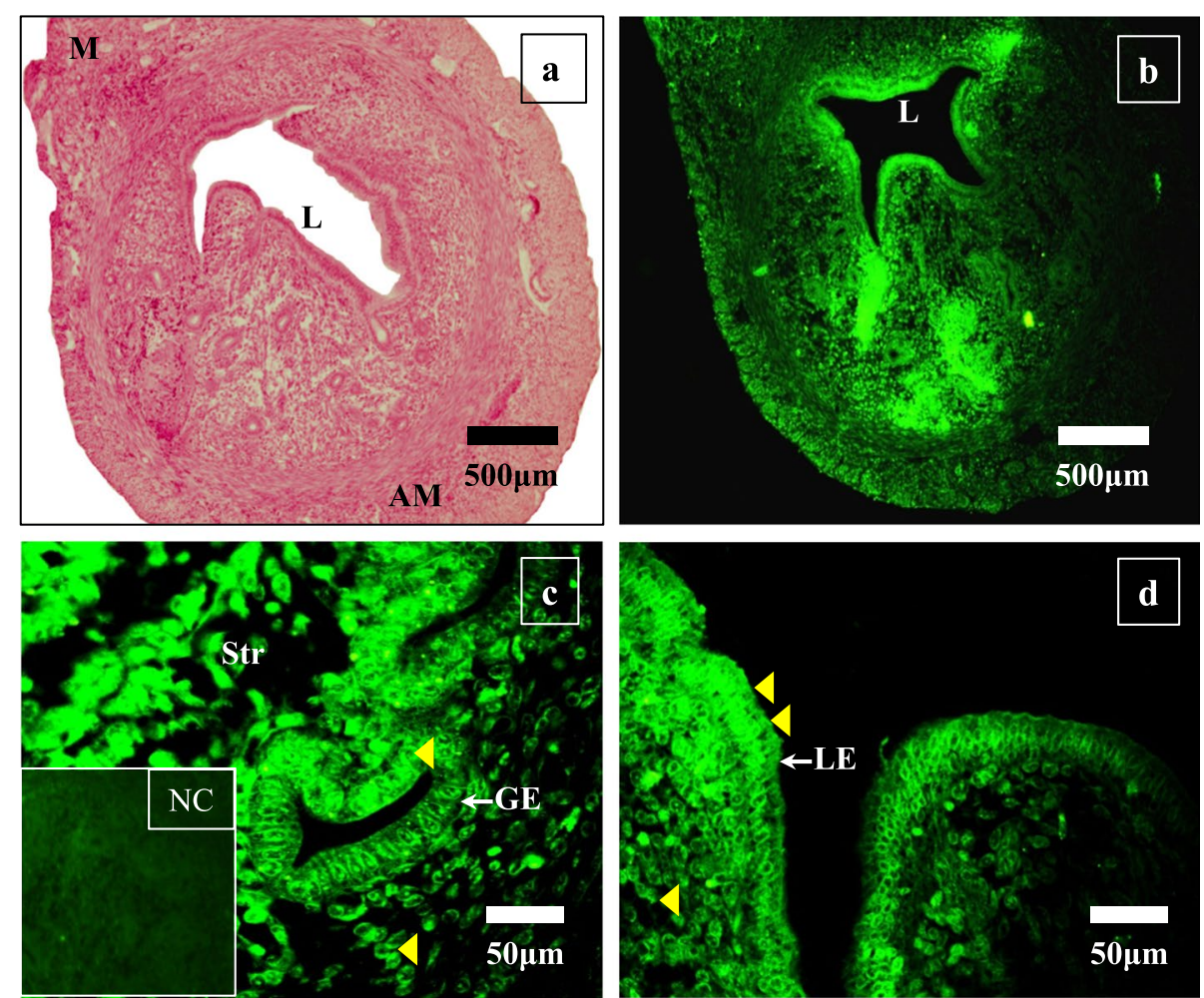

Fig. 8 Immunofluorescence of KLF5 on AntiE2-treated D4 mice uterus using FITC-conjugated antibody. The protein was localized in the luminal epithelium (LE), glandular epithelium (GE) of uterine glands, and stroma (Str). The arrowhead indicates the expression. Original magnification: a $5 \times$, b 5x, c 40x, d 40x. L, lumen; M, mesometrial pole; AM, antimesometrial pole; NC, negative control

studied the expression pattern of Klf5 during the periimplantation period. The effect of antiestrogen (ICI $182,780)$ and antiprogesterone (RU486) on the expression pattern of Klf5 has also been studied in the present study.

Embryo implantation is the process of a tightly regulated sequence of events. The blastocysts remain floated in the uterine lumen for a certain period before implantation [29]. D4.5 of gestation is the crucial time for uterine receptivity. During this time, the plasma membrane of uterine luminal epithelium undergoes drastic changes to make non-receptive uterus to the receptive state through an event known as plasma membrane transformation [30]. Under the influence of ovarian steroids, the uterine lumen changes to a slit-like structure which contributes to the apposition of blastocyst trophectoderm to the uterine luminal epithelium. The luminal epithelium is the first layer that comes in contact with implanting blastocyst. The KLF5 protein is localized in the luminal and glandular epithelium by Immunofluorescence study on D4 of gestation. From the results obtained, it can be speculated that this factor may have some role in epithelial cell differentiation and glandular secretion, which are prerequisites for implantation initiation. Localization of
KLF5 in proliferating stromal cells indicates its role in embryo maintenance.

With the initiation of implantation, the embryos in the blastocyst stage are encased in a crypt (implantation chamber) formed by evaginations of luminal epithelium towards the antimesometrial pole for proper homing of the embryo. The ICM of the embryo is facing towards the mesometrial pole surrounded by polar trophectoderm. During this period, the transcription factor is localized in various embryo and uterus cell types. The stromal cells adjacent to implanting blastocyst undergo decidualization to form the primary decidual zone (PDZ) on D5 of gestation. Localization of KLF5 protein in the PDZ on D5 of gestation indicates its role in PDZ formation. PDZ acts as a barrier restricting the migration of immune cells or any undesired matters from the maternal circulation to the embryo. Results of our present study showed localization of KLF5 in the luminal epithelium and glandular epithelium suggests its role in embryo attachment and glandular secretion. With the progression of gestation, the lateral luminal epithelium surrounding the blastocyst undergoes apoptosis or entosis by the trophectodermal cell to accommodate the embryo in the stromal compartment $[6,31]$. In conditionally ablated Klf5 mice uterus, 

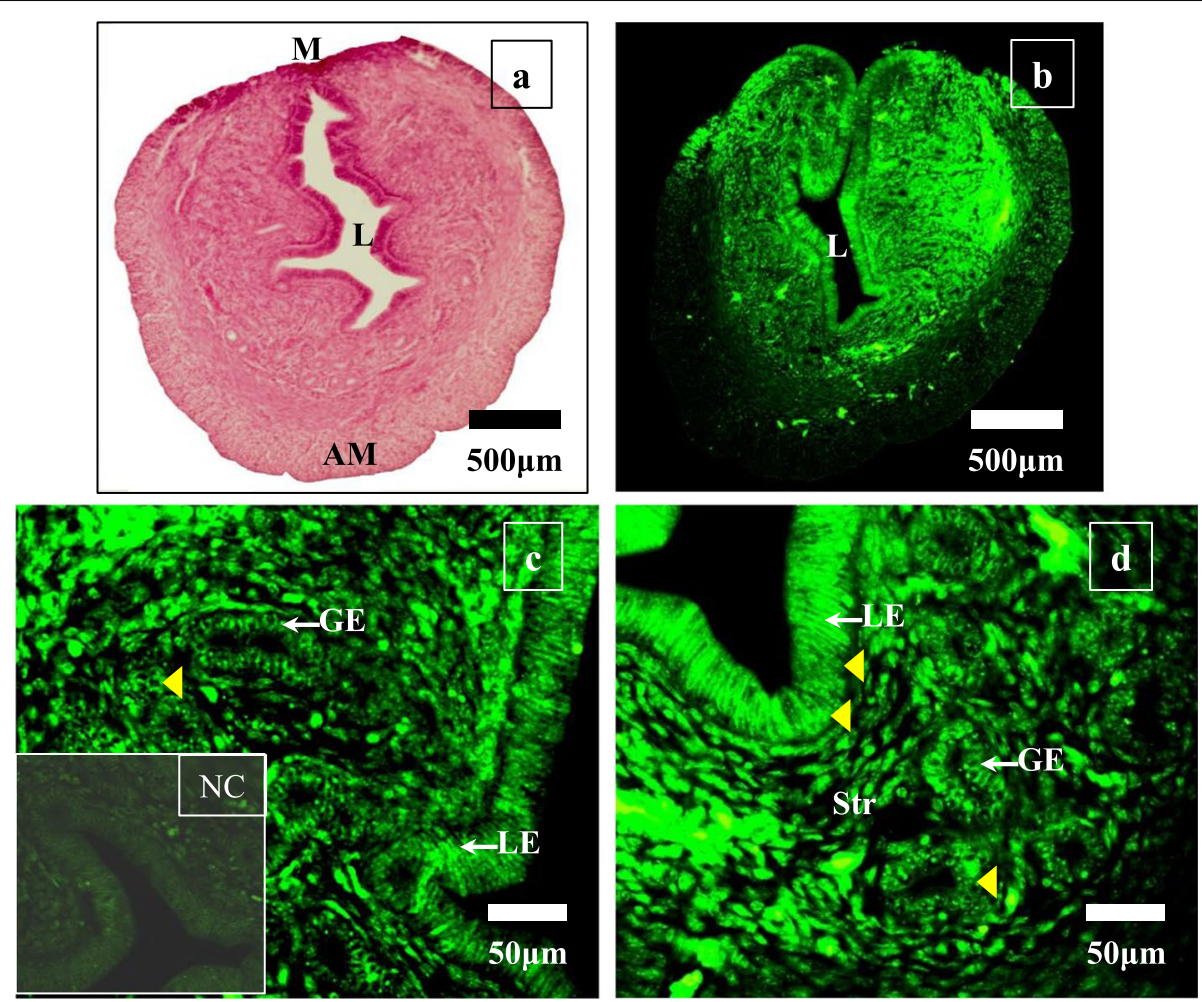

Fig. 9 Immunofluorescence of KLF5 on AntiP4-treated D4 mice uterus using FITC-conjugated antibody. The protein was localized in the luminal epithelium (LE) and glandular epithelium (GE) of uterine glands and stroma (Str). The arrowhead indicates the expression. Original magnification: a $5 \times$, b $5 \times$, c $40 \times$, d $40 \times$. L, lumen; M, mesometrial pole; AM, antimesometrial pole; NC, negative control

the luminal epithelium remains intact at this particular time leading to implantation failure [15]. This suggests the role of Klf5 in luminal epithelial disintegration and successful embryo implantation.

On D6 of gestation, the embryo has invaded into the antimesometrial stromal layer, which is undergoing decidualization to form PDZ. The stromal cells next to PDZ start to undergo decidualization forming the secondary decidual zone (SDZ). The decidua provides nutrition and protection to the growing embryo. Our results showed the expression of the KLF5 transcription factor in the embryo and uterine compartment. The results obtained on D6 of gestation suggest that Klf5 has a role in the development of the embryo. Expression of this protein observed in the PDZ and SDZ of the uterine compartment suggests its critical role in the decidualization process, embryo invasion in maternal tissues, and stromal epithelial cross-talk during implantation.

The PDZ undergoes apoptosis to accommodate the growing embryo with the advancement of pregnancy. To meet the high energetic demand of decidualization, autophagy is important [32]. The KLF5 protein is localized in the proliferating stromal cells of PDZ and SDZ, ascertaining the role of this transcription factor in programmed decidualization and autophagy. On D7 of gestation, the egg cylinder becomes elongated. The expression of growth factor has been observed in the ectoplacental cone (EPC), distal endoderm, mural trophectoderm, primitive streak, and embryonic ectoderm on the D7 embryo. The developmental role of this transcription can be ascertained by looking at the results obtained.

On D8 of gestation, there is continuous disintegration and degradation of PDZ to make room for the developing embryo. The proliferating stromal cells of PDZ and SDZ show the localization of this transcription factor. These results consistently support the role of KLF5 in decidualization throughout the periimplantation period. The differential expression of KLF5 in various embryo cell types suggests the role of KLF5 in organogenesis.

To know the effect of estrogen and progesterone receptor antagonists, pregnant mice have been treated with the ovarian steroid antagonist. ICI 182,780 is an estrogen receptor antagonist which binds to both ER $\alpha$ and ER $\beta$. The antiestrogen binds to the estrogen receptors (ER) and leads to reduced dimerization of the receptor, causing rapid receptor degradation [33]. Nucleocytoplasmic shuttling of ER-ICI 182,780 complex is disrupted [34]. 

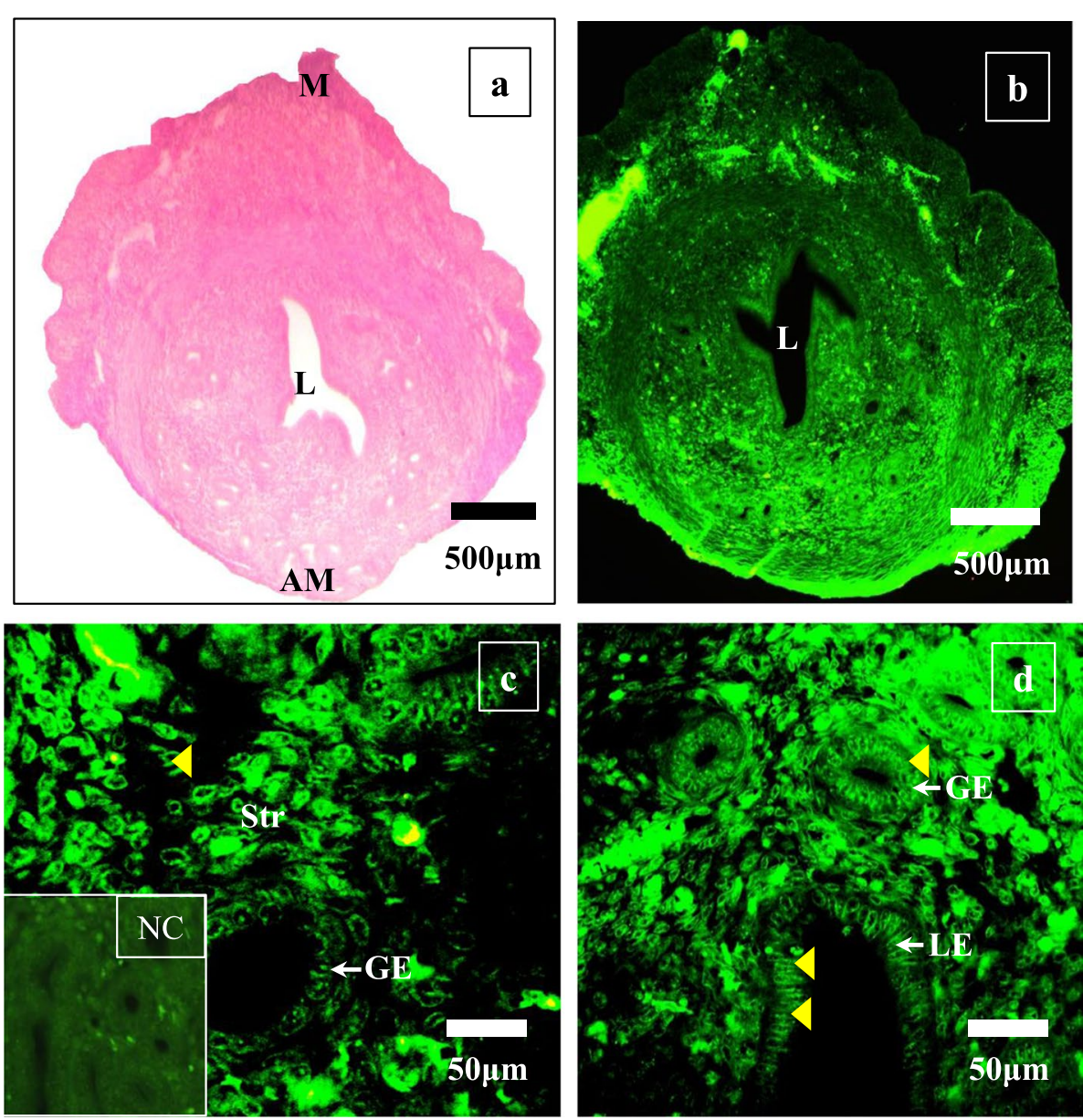

Fig. 10 Immunofluorescence of KLF5 on AntiE2+P4-treated D4 mice uterus using FITC-conjugated antibody. The protein was localized in the luminal epithelium (LE) and glandular epithelium (GE) of uterine glands and stroma (Str). The arrowhead indicates the expression. Original magnification: a 5x, b 5x, c 40x, d 40x. L, lumen; M, mesometrial pole; AM, antimesometrial pole; NC, negative control

Thus administration of ICI 182,780 blocks the activity of downstream targets of E2-ER signalling. In our present study, uterine luminal closure was not observed in the antiestrogen-treated mice uterus on $\mathrm{D} 4$ of gestation. The phenomenon of uterine luminal closure with the beginning of pregnancy has been considered one of the critical, required events of successful gestation. Antiestrogentreated mice uterus showed intense immunostaining of the transcription factor KLF5 in the luminal epithelium. A previous study showed that downregulation of KLF5 in the luminal epithelium is needed to make the uterus receptive [15]. Intense immunostaining of KLF5 in luminal epithelium indicated its non-receptivity. It can be inferred from the present investigation that KLF5 uses other pathways for its functioning. The expression of this transcription factor Klf5 could be estrogen-ER signalling independent during periimplantation in mice uterus.

Progesterone receptor antagonist RU486 binds to PR and leads to a conformational change in PR, making the receptor inactive. RU486 blocks the progesterone functions [35, 36]. Antiprogesterone, RU486, decreases the height of microvilli and pinopodes in the apical surface of the plasma membrane [36, 37]. RU486 inhibits the proliferation of stromal cells as the basic fibroblast growth factor expression in stromal cells is inhibited, leading to compromised decidualization [38, 39]. Since RU486 blocks progesterone signalling, extensive epithelial proliferation was observed. Compromised luminal closure and reduced stromal edema were observed in the RU486treated mice uterus when compared with D4. Intense expression of the transcription factor was observed in the luminal epithelium. From the findings of the present investigation, it has been speculated that KLF5 is not dependent upon the progesterone-PR pathway and operates in a different signalling cascade.

A similar expression pattern of the transcription factor was observed in the ICI 182,780+RU486-treated group. Co-treatment of antiestrogen and antiprogesterone 


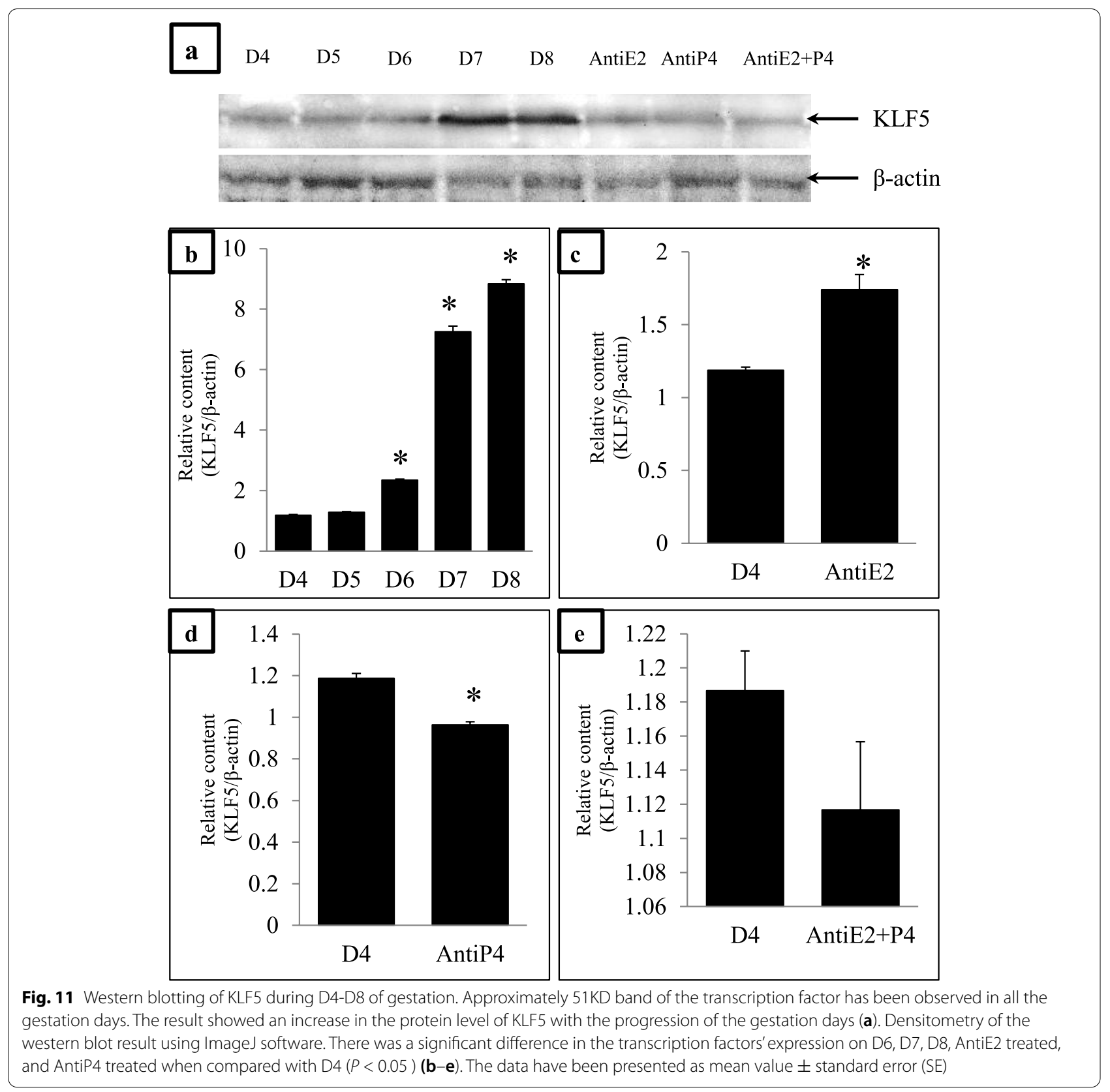

blocks both estrogen and progesterone signalling cascade in mice uterus. Estrogen-induced epithelial proliferation and progesterone-induced stromal cell proliferation has been blocked in the treated mice uterus leading to aberrant luminal closure. As KLF5 was localized in the luminal and glandular epithelium in the antagonist-treated mice, it is believed that the expression of this transcription factor is not dependent upon estrogen or progesterone signalling.

Western blot analysis in the present investigation showed the presence of this protein in D4-D8 of gestation. On D4 of gestation, the least KLF5 protein level was reported, whereas the highest protein level was reported in D8 of gestation. There was a gradual increase in the protein level of the transcription factor with the progression of gestation. From the results obtained, it has been deciphered that KLF5 has a crucial role in uterine receptivity, implantation, and decidualization. In the ovarian steroid antagonist-treated sample, the presence of KLF5 protein was observed. The result showed that the expression of KLF5 is not dependent upon ovarian steroids, estrogen and progesterone. We can say from our 

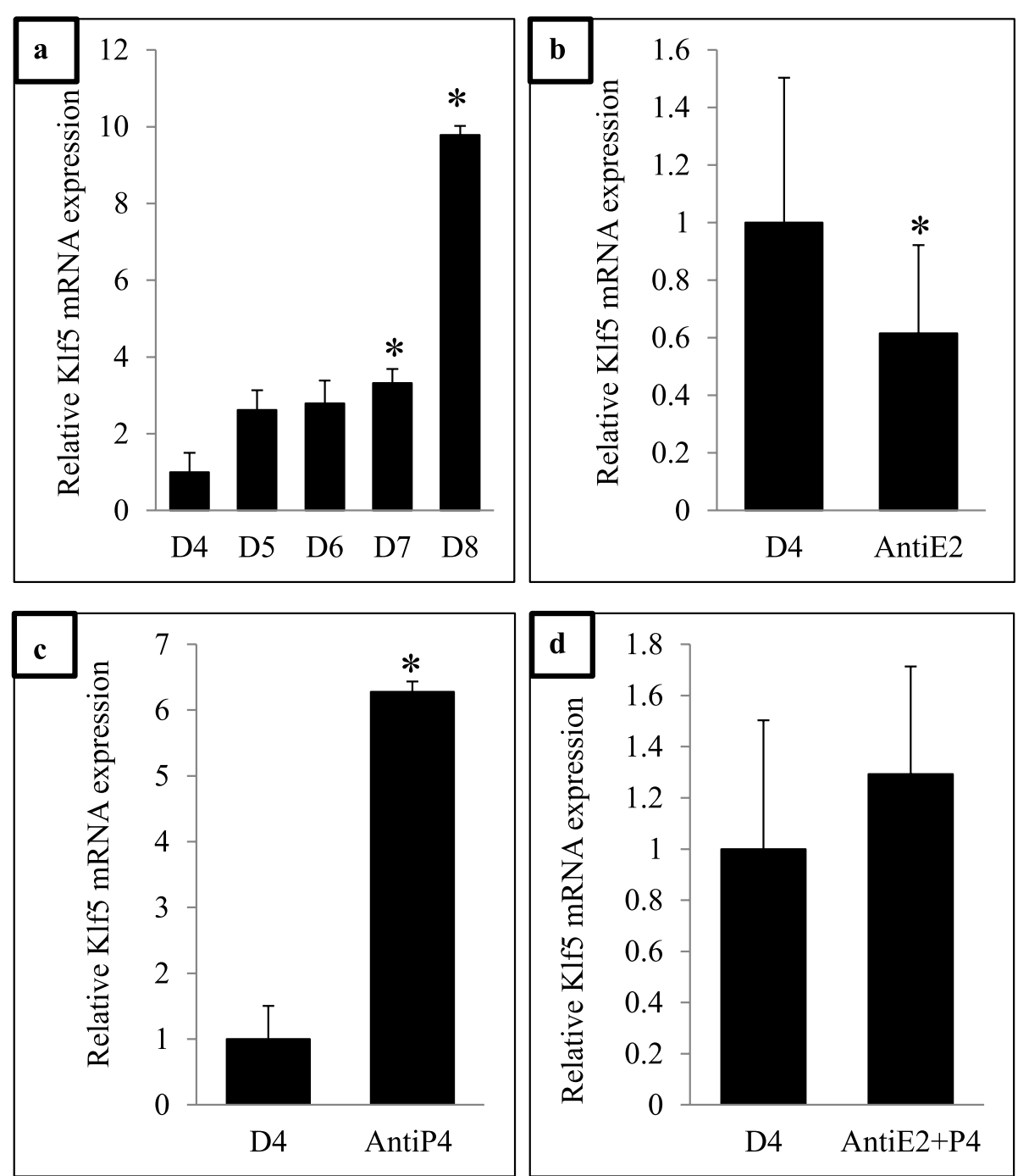

Fig. 12 Quantitative Real-Time PCR of Klf5 during D4 to D8 of gestation and in E2 and P4 antagonist treated uterus. The result revealed that KIf5 mRNA level is upregulated with the progression of gestation days (a), and there was a significant difference of KIf5 mRNA expression on D7, D8, and AntiP4-treated sample when compared with the D4 sample $(P<0.05)(\mathbf{b}-\mathbf{d})$. The data are represented as mean fold induction \pm SEM $(P<0.05)$

findings that KLF5 has a paramount role in the implantation and maintenance of pregnancy.

Our real-time PCR result showed Klf5 mRNA transcript was upregulated with the progression of gestation from D4-D8. The presence of Klf5 mRNA transcript in ovarian steroid antagonist-treated mice uterus on D4 of gestation points out that the expression of this transcription factor is not dependent on key ovarian steroids, estrogen and progesterone.

\section{Conclusion}

Considering the results obtained from this study, it is possible to state that Klf5 plays an active role in uterine receptivity, implantation, decidualization, and early embryogenesis. The spatiotemporal expression pattern of Klf5 during the periimplantation period would provide valuable insight into successful embryo implantation. The steroid-independent protein study will give a new understanding of the complex process of pregnancy in humans.

\section{Abbreviations}

AM: Antimesometrial pole; AntiE2: Antiestrogen; AntiE2+P4: Antiestrogen + antiprogesterone; AntiP4: Antiprogesterone; B: Blastocoel; E: Embryo; E2: Estrogen; EPC: Ectoplacental cone; ER: Estrogen receptor; GE: Glandular epithelium; ICM: Inner cell mass; KIf5: Kruppel-like factor 5 mRNA, DNA, and gene; KLF5: Kruppel-like factor 5 protein; L: Lumen; LE: Luminal epithelium; M: Mesometrial pole; MTE:: Mural trophectoderm; P4: Progesterone; 0.1\% PBS-T: 0.1\% Triton X-100 in phosphate-buffered saline; PBS-BSA: Bovine serum albumin in phosphate-buffered saline; PDZ: Primary decidual zone; PR: Progesterone receptor; PSC:: Proliferating stromal cell; PTE: Polar trophectoderm; QPCR: 
Quantitative polymerase chain reaction; RIPA buffer: Radioimmunoprecipitation assay buffer; SDZ: Secondary decidual zone; Str: Stroma; TBS: Tris-buffered saline; TBS-T: Tris-buffered saline Tween20; TGC: Trophoblast giant cell; VSF: Vascular sinusoidal fold; YC: Yolk cavity.

\section{Acknowledgements}

The authors are sincerely thankful to University Grants Commission for providing CSIR-UGC NET Fellowship. Authors acknowledge the Centre with potential for excellence in Biodiversity (CPEB-II), Rajiv Gandhi University, for providing research and financial assistance.

\section{Authors' contributions}

KRT contributed to the design, experimental works, analysis of results, and drafting of the manuscript. PS contributed to the conception of the present investigation. HNS gave final approval for the version to be published. All authors have read and approved the manuscript.

\section{Funding}

CSIR-UGC NET Fellowship from University Grants Commission.

\section{Availability of data and materials}

All data generated or analyzed during this study are included in this published article.

\section{Declarations}

\section{Ethics approval and consent to participate}

The experimental procedures followed in the present investigation were approved by the Institutional Animal Ethical Committee of Rajiv Gandhi University with ethical approval number IEAC/RGU/17/15. Consent to participate is not applicable.

\section{Consent for publication}

Not applicable.

\section{Competing interests}

The authors declare that there is no conflict of interest.

\section{Author details}

${ }^{1}$ Molecular Endocrinology \& Reproductive Biology Research Laboratory, Department of Zoology, Rajiv Gandhi University, Rono Hills, Itanagar, Arunachal Pradesh 791 112, India. ${ }^{2}$ Department of Zoology, Dhemaji College, Dhemaji, Assam 787057, India.

Received: 25 June 2021 Accepted: 22 December 2021

Published online: 07 January 2022

\section{References}

1. Fukui Y, Hirota Y, Matsuo M, Gebril M, Akaeda S, Hiraoka T, Osuga Y (2019) Uterine receptivity, embryo attachment, and embryo invasion: multistep processes in embryo implantation. Reprod Med Biol 18:234-240

2. Egashira M, Hirota Y (2013) Uterine receptivity and embryo-uterine interactions in embryo implantation: lessons from mice. Reprod Med Biol 12:127-132. https://doi.org/10.1007/s12522-013-0153-1

3. Yuan J, Deng W, Cha J, Sun X, Borg JP, Dey SK (2018) Tridimensional visualization reveals direct communication between the embryo and glands critical for implantation. Nat Commun 9(1):603. Published 2018 Feb 9. https://doi.org/10.1038/s41467-018-03092-4

4. Schlafke S, Enders AC (1975) Cellular basis of interaction between trophoblast and uterus at implantation. Biol Reprod 12(1):41-65. https://doi.org/ 10.1095/biolreprod12.1.41

5. Enders AC, Schlafke S (1978) Comparative aspects of blastocyst-endometrial interactions at implantation. Ciba Found Symp 64:3-32. https://doi. org/10.1002/9780470720479.ch2

6. Li Y, Sun X, Dey SK (2015) Entosis allows timely elimination of the luminal epithelial barrier for embryo implantation. Cell Rep 11(3):358-365. https://doi.org/10.1016/j.celrep.2015.03.035
7. Kelleher AM, Burns GW, Behura S, Wu G, Spencer TE (2016) Uterine glands impact uterine receptivity, luminal fluid homeostasis and blastocyst implantation. Sci Rep 6:38078. Published 2016 Dec 1. https://doi.org/10. 1038/srep38078

8. Harper MJ (1992) The implantation window. Baillieres Clin Obstet Gynaecol 6(2):351-371. https://doi.org/10.1016/s0950-3552(05)80092-6

9. Wang H, Dey SK (2006) Roadmap to embryo implantation: clues from mouse models. Nat Rev Genet 7(3):185-199. https://doi.org/10.1038/ nrg1808

10. Conneely OM, Mulac-Jericevic B, DeMayo F, Lydon JP, O’Malley BW (2002) Reproductive functions of progesterone receptors. Recent Prog Horm Res 57:339-355. https://doi.org/10.1210/rp.57.1.339

11. Lubahn DB, Moyer JS, Golding TS, Couse JF, Korach KS, Smithies O (1993) Alteration of reproductive function but not prenatal sexual development after insertional disruption of the mouse estrogen receptor gene. Proc Natl Acad Sci U S A 90(23):11162-11166. https://doi.org/10.1073/pnas.90. 23.11162

12. Lee KY, Jeong JW, Tsai SY, Lydon JP, DeMayo FJ (2007) Mouse models of implantation. Trends Endocrinol Metab 18(6):234-239. https://doi.org/10. 1016/j.tem.2007.06.002

13. Cha J, Sun X, Dey SK (2012) Mechanisms of implantation: strategies for successful pregnancy. Nat Med 18(12):1754-1767. https://doi.org/10. 1038/nm.3012

14. Zhang S, Kong S, Lu J, Wang Q, Chen Y, Wang W, Wang B, Wang H (2013) Deciphering the molecular basis of uterine receptivity. Mol Reprod Dev $80(1): 8-21$

15. Sun X, Zhang L, Xie H, Wan H, Magella B, Whitsett J, Dey S (2012) Kruppellike factor 5 (KLF5) is critical for conferring uterine receptivity to implantation. Proc Natl Acad Sci 109:1145-1150

16. Ema M, Mori D, Niwa H, Hasegawa Y, Yamanaka Y, Hitoshi S, Mimura J, Kawabe Y, Hosoya T, Morita M, Shimosato D, Uchida K, Suzuki N, Yanagisawa J, Sogawa K, Rossant J, Yamamoto M, Takahashi S, Fujii-Kuriyama Y (2008) Kruppel-like factor 5 is essential for blastocyst development and the normal self-renewal of mouse ESCs. Cell Stem Cell 3(5):555-567

17. Lin SC, Wani MA, Whitsett JA, Wells JM (2010) Klf5 regulates lineage formation in the preimplantation mouse embryo. Development 137(23):3953-3963. https://doi.org/10.1242/dev.054775

18. Psychoyos A (1973) Hormonal control of ovoimplantation. Vitam Horm 31:201-256. https://doi.org/10.1016/s0083-6729(08)60999-1

19. Deb K, Reese J, Paria BC (2006) Methodologies to study implantation in mice. Methods Mol Med 121:9-34. https://doi.org/10.1385/1-59259-9834:007

20. Zhang P, Tang M, Zhong T, Lin Y, Zong T, Zhong C, Zhang B, Ren M, Kuang $H$ (2014) Expression and function of kisspeptin during mouse decidualization. PloS one 9(5):e97647. https://doi.org/10.1371/journal.pone.00976 47

21. Cheon YP, Li Q, Xu X, DeMayo FJ, Bagchi IC, Bagchi MK (2002) A genomic approach to identify novel progesterone receptor regulated pathways in the uterus during implantation. Mol Endocrinol 16(12):2853-2871. https://doi.org/10.1210/me.2002-0270

22. Eminaga S, Teekakirikul P, Seidman CE, Seidman JG (2016) Detection of cell proliferation markers by immunofluorescence staining and microscopy imaging in paraffin-embedded tissue sections. Curr Protoc Mol Biol 115:14.25.1-14.25.14. https://doi.org/10.1002/cpmb.13 PMID: 27366888; PMCID: PMC5349766

23. Lowry O, Rosebrough N, Farr A, Randall R (1951) Protein measurement with the Folin phenol reagent. J Biol Chem 193(1):265-275

24. Gallagher SR (2006) One-dimensional SDS gel electrophoresis of proteins. In: Ausubel FM, Brent R, Kingston RE, Moore DD, Seidmen JG, Smith JA, Atruhl K (eds) Current protocols in molecular biology. Wiley, United States. pp 10.2A.1-10.2A.34. https://doi.org/10.1002/0471142727.mb100 2as75

25. Fraga D, Meulia T, Fenster S (2008) Real-time PCR. In: Current protocols essential laboratory techniques, pp 10.3.1-10.3.34. https://doi.org/10. 1002/9780470089941.et1003s00

26. Livak KJ, Schmittgen TD (2001) Analysis of relative gene expression data using real-time quantitative PCR and the 2(-delta delta $C(T)$ ) method. Methods. 25(4):402-408. https://doi.org/10.1006/meth.2001.1262

27. Massimiani M, Lacconi V, La Civita F, Ticconi C, Rago R, Campagnolo L (2019) Molecular signaling regulating endometrium-blastocyst crosstalk. 
Int J Mol Sci 21(1):23. Published 2019 Dec 18. https://doi.org/10.3390/ ijms 21010023

28. Idelevich A, Vilella F (2020) Mother and embryo cross-communication. Genes (Basel) 11(4):376. Published 2020 Mar 31. https://doi.org/10.3390/ genes 11040376

29. Li Q, Davila J, Bagchi MK, Bagchi IC (2016) Chronic exposure to bisphenol a impairs progesterone receptor-mediated signaling in the uterus during early pregnancy. Recept Clin Investig 3(3):e1369. https://doi.org/10. $14800 /$ rci.1369

30. Murphy C (2001) The plasma membrane transformation: a key concept in uterine receptivity. Reprod Med Rev 9:197-208

31. Parr E, Tung H, Parr M (1987) Apoptosis as the mode of uterine epithelial cell death during embryo implantation in mice and rats. Biol Reprod 36(1):211-225

32. Choi S, Shin H, Song H, Lim H (2014) Suppression of autophagic activation in the mouse uterus by estrogen and progesterone. J Endocrinol 221(1):39-50

33. Howell A, Osborne C, Morris C. Wakeling A (2000) ICI 182,780 (Faslodex ${ }^{\mathrm{TM}}$ ): development of a novel, "pure" antiestrogen. Cancer 89(4):817-825 (https://doi.org/10.1002/1097-0142(20000815)89:4<817::AID-CNCR14>3. $0 .(\mathrm{CO} ; 2-6)$

34. Dauvois S, White R, Parker M (1993) The antiestrogen ICI 182780 disrupts estrogen receptor nucleocytoplasmic shuttling. J Cell Sci 106(Pt 4):1377-1388

35. Spitz I (2003) Progesterone antagonists and progesterone receptor modulators: an overview. Steroids 68:981-993

36. Gafari F, Afshari F, Taghizadieh M (2016) The Assessment of the ultrastructure of luminal epithelium in the endometrium after the application of antiprogesterone. Cresc J Med Biol Sci 4(1):28-31

37. Scholtz KE, Penny CB, Hosie MJ (2008) A high resolution SEM study of the effects of RU486, used as a postcoital contraceptive, on the rat uterus during early pregnancy. Cell Biol Int 32(4):436-446. https://doi.org/10. 1016/j.cellbi.2007.12.015

38. Rider V, Psychoyos A (1994) Inhibition of progesterone receptor function results in loss of basic fibroblast growth factor expression and stromal cell proliferation during uterine remodelling in the pregnant rat. J Endocrinol 140(2):239-249

39. Parandoosh Z, Crombie DL, Tetzke TA, Hayes J, Heap RB, Wang MW (1995) Progesterone and oestrogen receptors in the decidualized mouse uterus and effects of different types of anti-progesterone treatment. J Reprod Fertil 105(2):215-220

\section{Publisher's Note}

Springer Nature remains neutral with regard to jurisdictional claims in published maps and institutional affiliations.

\section{Submit your manuscript to a SpringerOpen ${ }^{\odot}$ journal and benefit from:}

- Convenient online submission

- Rigorous peer review

- Open access: articles freely available online

- High visibility within the field

- Retaining the copyright to your article

Submit your next manuscript at $\boldsymbol{\nabla}$ springeropen.com 